Original Article

\title{
Gender and posture are significant risk factors to musculoskeletal symptoms during touchscreen tablet computer use
}

\author{
Szu-Ping Lee, PT, PhD ${ }^{1)^{*}}$, Ya-Ting Hsu, PT, PhD ${ }^{1,2)}$, Betina Bair, PT, DPT ${ }^{3)}$, \\ Marissa Toberman, PT, DPT ${ }^{4}$, Lung-Chang Chien, DrPH ${ }^{5}$ \\ 1) Department of Physical Therapy, University of Nevada, Las Vegas: 4505 S. Maryland Parkway, Box \\ 453029, Las Vegas, NV 89154-3029, USA \\ 2) HealthSouth Rehabilitation Hospital of Henderson, USA \\ 3) Family and Sports Physical Therapy, USA \\ 4) Sunrise Hospital and Medical Center, USA \\ 5) Department of Environmental and Occupational Health, University of Nevada, Las Vegas, USA
}

\begin{abstract}
Purpose] To investigate the prevalence of neck and shoulder symptoms during the use of tablet computer, and to identify the risk factors associated with these symptoms. [Subjects and Methods] A cross-sectional survey was conducted to study tablet computer usage, posture during use, and neck and shoulder symptoms in 412 participants in a school setting. Significant risk factors for musculoskeletal symptoms during tablet computer use were identified. [Results] Overall prevalence of musculoskeletal symptoms during tablet computer use was $67.9 \%$ with greater prevalence of neck symptoms (neck: $84.6 \%$; shoulder/upper extremity: $65.4 \%$ ). Significant risk factors associated with symptoms during use were: current musculoskeletal symptoms, gender, roles, and postural factors including: sitting without back support, sitting with device in lap, and lying on the side and on the back during tablet computer use. A multivariate analysis further showed that the odds for females to have symptoms were 2.059 times higher than males. [Conclusion] The findings revealed that female gender and other postural factors were significantly associated with musculoskeletal symptoms during the use of tablet computer. Among all postural factors, sitting without back support was identified as the most important risk factor for having musculoskeletal symptoms. Key words: Pain, Posture, Gender
\end{abstract}

(This article was submitted Jan. 24, 2018, and was accepted Mar. 27, 2018)

\section{INTRODUCTION}

Neck and shoulder musculoskeletal symptoms are common health complaints. A recent epidemiologic study by Hoy et al. demonstrated that the annual incidence rate of neck pain to be $10.4-21.3 \%$ with a higher rate for office and computer workers $^{1)}$. In the college student population, a one-year prospective cohort study demonstrated a high incidence rate at $46 \%$ and of whom $33 \%$ reported persistent neck pain ${ }^{2}$. Such high prevalence of neck and shoulder symptoms, especially among the younger populations, presents a substantial burden to the society.

Musculoskeletal symptoms of the neck and shoulder are theorized to have a multi-factorial origin including physical and demographic contributors ${ }^{2-5)}$. Current evidence suggests that significant risk factors include female gender ${ }^{1,2,6)}$, having high job demands ${ }^{7)}$, and having a history of spinal disorders ${ }^{8}$. Noticeably, some physical factors are associated with neck pain, including prolonged computer work for students ${ }^{9-11)}$ and prolonged sitting and neck flexion for office workers ${ }^{12)}$. A systematic review regarding individuals with documented musculoskeletal disorders showed an association between computer use

*Corresponding author. Szu-Ping Lee (E-mail: szu-ping.lee@unlv.edu)

(C2018 The Society of Physical Therapy Science. Published by IPEC Inc.

(c) (i) $\odot$ This is an open-access article distributed under the terms of the Creative Commons Attribution Non-Commercial No DerivaCC BY NC ND tives (by-nc-nd) License. (CC-BY-NC-ND 4.0: https://creativecommons.org/licenses/by-nc-nd/4.0/) 
and tension neck syndrome ${ }^{13}$. It is logical that posture and workplace ergonomics are related to the development of neck and shoulder symptoms. For example, Marcus et al. found that keying with a more extended elbow, proper head tilt, and use of arm rests could reduce the risk of developing neck and shoulder disorders ${ }^{14)}$. Since computer use often involves maintaining the same posture for prolonged periods of time, the muscles of the neck and shoulder may become overworked. Several studies have documented a relationship between trapezius muscle load and the development of musculoskeletal discomfort in the upper body $\left.{ }^{15}, 16\right)$.

In recent years, the use of touchscreen tablet computers has increased dramatically. According to the report from the International Data Corporation in 2013, tablet computers account for $14.6 \%$ of all connected-device market, and the growth rate of these devices was expected to be the highest over the next few years ${ }^{17)}$. Findings from an industrial survey in 2013 in the U.S. showed that $43 \%$ of the population owns a tablet computer or e-book reader ${ }^{18)}$. The ownership and usage of such devices are perhaps even higher among the student population ${ }^{19}$. Despite the increased popularity of the tablet computers, the device is new enough that only few studies have investigated the association between its usage and musculoskeletal disorders. A recent study in a university population showed significant associations between the total time spent using a mobile phone and pain in the neck and shoulder regions ${ }^{20)}$.

Ergonomic studies have suggested that the use of mobile electronic devices such as laptop computers exhibits the tendency to lead to even poorer head and neck posture than desktop computers ${ }^{21)}$. With mobile devices, one's posture often depends on the available supporting surfaces and environments (e.g. holding a device in hand while sitting in a chair). Prolonged cervical flexion is commonly observed when the tablet computer is placed flat on a desk or when held in a position below eye level. This may cause the cervical extensor muscles to lengthened and put a larger load on these muscles ${ }^{22}$. It is logical that the postures users assume when using tablet computers can have implications for developing neck and shoulder symptoms.

The purposes of the current study was to 1) investigate the prevalence of neck and shoulder symptoms during use of tablet computers, and 2) identify the risk factors associated with the symptoms during device use.

\section{SUBJECTS AND METHODS}

A cross-sectional survey was developed and distributed to a public university population. Self-reported usage of touchscreen tablet computers, usage behavior, musculoskeletal complaints, and demographic data were collected via an online survey using Qualtrics Research Suite (Qualtrics, LLC.) in a 3-month period.

Participants were recruited using word of mouth solicitation and online communication. The inclusion criteria are: 1) having access to the online survey, 2) being able to read the survey written in English, and 3) being a university student, staff, faculty, or alumni. The word of mouth solicitation consisted of visits to university faculty and staff, presenting the survey to various undergraduate classes, and soliciting the survey on campus. Online communication consisted of social media, university mass email announcements, campus newsletters, and an access link to the survey on the university website. The study was approved by the Institutional Review Board for Biomedical Research at the University of Nevada, Las Vegas and exempted from written consent.

The online questionnaire was composed of 22 items in 3 categories: 1) demographic information, 2) typical device usage behavior, and 3) current neck and shoulder symptoms and symptoms during use which include duration, types, severity, and location of symptoms. We limited our study to the ownership of tablet computers only (with a diagonal dimension from 9-10 inches to 4-6 inches), and not smart phones. All the items related to specific postures (including the use of tablet support), environments, and symptom locations were illustrated to help participants understand the description correctly. The questionnaire was reviewed and revised by two experts in the field of the musculoskeletal science and clinical practice to establish face validity. Also, a preliminary study was conducted to examine the reliability of the survey.

The collected data were analyzed using the Statistical Packet for the Social Sciences (IBM SPSS Statistics Version 22.0, International Business Machines Corp., New York, USA). Descriptive statistics were used to report the prevalence of musculoskeletal symptoms of neck and shoulder, and various postural factors. The collected data, except for severity of symptoms, are categorical, including gender, age group, role, and typical time of use ( $<3$ hours, 3-6 hours, and $>6$ hours). Other variables are dichotomous and answered by "yes" or "no", such as current symptoms, symptoms during use and postural factors.

Chi-Square analyses were conducted to examine significant risk factors associated with current symptoms and symptoms during device use at the univariate level. The identified risk factors were then entered into a logistic regression model to examine the association at the multivariate level. Specifically, the regression model investigated the contribution of sitting postures, demographic, and behavioral risk factors related to symptoms during tablet use. Furthermore, the Homsmer and Lemeshow test for logistic regression was conducted to examine the goodness of fit. Odds ratios were reported to compare the effects of the risk factors included in the model. The significant level was set at 0.05 . Since researchers intended to liberally explore potential risk factors, variables with a p-value between $0.05-0.08$ at the univariate level were included in the multivariate logistic regression model. 
Table 1. Participant demographics, tablet computer ownership, usage time, and symptoms

\begin{tabular}{|c|c|c|}
\hline & $\begin{array}{c}\text { Percentage } \\
(\%)\end{array}$ & $\begin{array}{c}\text { Frequency } \\
(\mathrm{N}=412)\end{array}$ \\
\hline \multicolumn{3}{|l|}{ Age (years) } \\
\hline $18-25$ & 60.2 & 248 \\
\hline $26-39$ & 19.4 & 80 \\
\hline $40-59$ & 16.0 & 66 \\
\hline$\geq 60$ & 3.4 & 18 \\
\hline Missing & 1.0 & 4 \\
\hline \multicolumn{3}{|l|}{ Role } \\
\hline Student & 68.9 & 284 \\
\hline Faculty & 12.4 & 51 \\
\hline Staff & 10.4 & 43 \\
\hline Alumni & 7.0 & 29 \\
\hline Missing & 1.2 & 5 \\
\hline \multicolumn{3}{|c|}{ Tablet computer ownership } \\
\hline Yes & 76.5 & 315 \\
\hline No & 23.5 & 97 \\
\hline \multicolumn{3}{|c|}{ Current neck/shoulder symptoms } \\
\hline Yes (symptomatic) & 60.0 & 247 \\
\hline \multirow[t]{2}{*}{ No } & 40.0 & 165 \\
\hline & $\begin{array}{c}\text { Percentage } \\
(\%)\end{array}$ & $\begin{array}{l}\text { Frequency } \\
(\mathrm{N}=315)^{\dagger}\end{array}$ \\
\hline \multicolumn{3}{|l|}{ Tablet use time (hours) } \\
\hline$<3$ & 57.1 & 180 \\
\hline $3-6$ & 23.2 & 73 \\
\hline$>6$ & 19.7 & 62 \\
\hline \multicolumn{3}{|c|}{ Neck/shoulder symptoms during Use } \\
\hline Yes (symptomatic) & 67.9 & 214 \\
\hline No & 32.1 & 101 \\
\hline
\end{tabular}

†Individuals who own table computers only.

\section{RESULTS}

The final sample size of this survey was 412 (135 men and 275 women). Since two participants preferred not to identify their gender, the two cases were excluded from analyses related to gender. A summary of the demographic information of the participants is included in Table 1.

315 out of 412 participants (76.5\%) reported owning at least one touchscreen tablet computer. Most of the device owners have a typical device usage time of less than 3 hours per day (57.1\%). Prevalence of symptoms during tablet use was $67.9 \%$ (Table 1). For device users with musculoskeletal symptoms during use, most symptoms were reported in the neck (84.6\%), upper back/shoulder $(65.4 \%)$, arms/hands $(33.6 \%)$, and head (15.0\%). The most common types of symptoms are stiffness (74.3\%), soreness (48.1\%) and aching or pain (42.5\%). The most severe level of discomfort during tablet use was moderate $(55.4 \%)$, but noticeably, $10.0 \%$ of participants reported severe symptoms (i.e. $7-10$ on a 10-point Visual Analog Scale). Only $46.1 \%$ of the respondents reported that they would stop using the device when experiencing discomforts using device use. $15 \%$ of the users reported that the symptoms affect their sleep.

Gender comparison for symptoms during tablet use was summarized in Table 2. Significant gender difference in symptom prevalence was observed ( $\mathrm{p}=0.019)$ : $70.1 \%$ of the female respondents reported to experience symptoms in comparison to only $29.9 \%$ among the male respondents. During tablet use, significantly more women reported symptoms in the upper back and shoulder region than men (75.7 vs. $24.3 \%$; $\mathrm{p}=0.014)$. In addition, $77.0 \%$ of women reported using their devices while sitting on floor, comparing to only $23.0 \%$ in men $(\mathrm{p}=0.02)$.

Chi-square analysis identified two significant factors associated with current symptoms: role (faculty, staff, alumni, and students; $p=0.041)$ and symptom during use $(\mathrm{p}<0.001$; Table 3$)$. For risk factors associated with symptoms during device use, the results showed that role $(\mathrm{p}=0.022)$ and female gender $(\mathrm{p}=0.019)$ are significant factors. Also, daily time of usage exhibited 
Table 2. Effect of gender on musculoskeletal symptoms during tablet computer use

\begin{tabular}{|c|c|c|c|c|c|}
\hline & \multicolumn{2}{|c|}{$\begin{array}{c}\text { Women } \\
(\mathrm{N}=275)\end{array}$} & \multicolumn{2}{|c|}{$\begin{array}{c}\text { Men } \\
(\mathrm{N}=135)\end{array}$} & \multirow[b]{2}{*}{ p-value } \\
\hline & $\mathrm{N}$ & $\%$ & $\mathrm{~N}$ & $\%$ & \\
\hline \multicolumn{6}{|l|}{ Symptoms during use } \\
\hline Yes & 193 & 70.1 & 40 & 29.9 & \multirow{2}{*}{0.019} \\
\hline No & 82 & 29.8 & 95 & 70.4 & \\
\hline \multicolumn{6}{|c|}{ Regions of symptoms during use } \\
\hline Head & 180 & 65.6 & 46 & 34.4 & 0.549 \\
\hline Neck & 187 & 68.0 & 43 & 32.0 & 0.110 \\
\hline Upper back/Shoulder & 208 & 75.7 & 33 & 24.3 & 0.014 \\
\hline Arm/Hand & 191 & 69.4 & 41 & 30.6 & 0.883 \\
\hline
\end{tabular}

Table 3. Demographic factors associated with current musculoskeletal symptoms

\begin{tabular}{|c|c|c|c|c|c|}
\hline & \multicolumn{4}{|c|}{ Current musculoskeletal symptoms } & \multirow[b]{3}{*}{ p-value } \\
\hline & \multicolumn{2}{|c|}{ with } & \multicolumn{2}{|c|}{ without } & \\
\hline & $\mathrm{N}$ & $\%$ & $\mathrm{~N}$ & $\%$ & \\
\hline Role & & & & & 0.041 \\
\hline Student & 163 & 57.4 & 121 & 42.6 & \\
\hline Faculty & 28 & 54.9 & 23 & 45.1 & \\
\hline Staff & 33 & 76.7 & 10 & 23.3 & \\
\hline Alumni & 21 & 72.4 & 8 & 27.6 & \\
\hline Gender & & & & & 0.054 \\
\hline Female & 174 & 63.3 & 101 & 36.7 & \\
\hline Male & 72 & 53.3 & 63 & 46.7 & \\
\hline
\end{tabular}

a trend of positive association ( $\mathrm{p}=0.075)$. When examining risk factors while sitting, sitting without back support ( $\mathrm{p}=0.016)$ and sitting with the device in lap $(\mathrm{p}=0.002)$ are significant postural factors associated with symptoms during use. When sitting in a chair at a desk, placing the device flat on the desk surface also exhibited a trend of association with symptom during use $(\mathrm{p}=0.053)$. Interestingly, we also found some of the more uncommon postures, including lying on the sides $(\mathrm{p}=0.002)$ and lying on the back $(\mathrm{p}=0.016)$ are significantly associated with symptoms during use (Table 4$)$. Since the primary interest is in sitting postures, these two variables were not further included in the regression model.

Based on the potential risk factors identified from the Chi-square analyses, the regression model included gender, role, use time, and sitting postures on a chair (without back support and device in lap) and at a desk (device placing flat on a table or desk). The model was significant $\left(\chi^{2}(9)=32.751, p<0.001\right)$ and the Hosmer and Lemeshow test indicated a good model fit $\left(\chi^{2}(8)=6.643, p=0.576\right)$. In the multivariate model, gender was again shown to be a significant predictor of symptoms during tablet computer use. The odds for women to have symptoms were 2.059 times higher than men. (Odds Ratio=2.059, 95\% CI $[1.211,3.502], \mathrm{p}=0.008)$. When controlling for the sitting postures, sitting in a chair without back support (Odds Ratio=2.231, 95\% CI [1.126, 4.419], $\mathrm{p}=0.021$ ) was the only significant postural factor. Also, being a university alumnus was a significant negative predictor of having symptoms when compare to being a current university student, (Odds Ratio $=0.310,95 \% \mathrm{CI}$ $[0.124,0.772], p=0.012)$. However, the model did not indicate usage hours being a positive predictor $(p=0.155)$.

A separate model was developed to assess specifically the sitting postures; we have identified specific postural factors associated with symptoms during the use of tablet computers, including sitting without back support ( $\mathrm{p}=0.016$ ) and sitting with device in the lap $(\mathrm{p}=0.002)$ based on Chi-square analyses. A multiple logistic regression analysis demonstrated that female gender $(\mathrm{p}=0.004)$ and sitting in a chair without back support $(\mathrm{p}=0.006)$ are the significant predictors of experiencing symptoms during the use of tablet computer.

\section{DISCUSSION}

With the increasing popularity of touchscreen tablet computers for personal, school, and business uses, it is pertinent to identify the prevalence and risk factors associated with musculoskeletal symptoms related to the use of such devices. Our study revealed that females and individuals with current musculoskeletal symptoms were more likely to be at risk for neck and shoulder symptoms. Certain postures during use were also identified as important risk factors, specifically sitting without 
Table 4. Risk factors associated with symptoms during device use

\begin{tabular}{|c|c|c|c|}
\hline & $\begin{array}{c}\% \text { with musculoskeletal } \\
\text { symptoms during tablet use }\end{array}$ & Frequency & $\mathrm{p}$-value \\
\hline Role & & & 0.022 \\
\hline Student & 73.4 & $152 / 207$ & \\
\hline Faculty & 54.5 & $24 / 44$ & \\
\hline Staff & 64.9 & $24 / 37$ & \\
\hline Alumni & 52.0 & $13 / 25$ & \\
\hline Gender & & & 0.019 \\
\hline Women & 72.8 & $150 / 206$ & \\
\hline Men & 59.8 & $64 / 107$ & \\
\hline Device usage hours & & & 0.075 \\
\hline$<3$ & 62.8 & $113 / 180$ & \\
\hline $3-6$ & 74.0 & $54 / 73$ & \\
\hline$>6$ & 75.8 & $47 / 62$ & \\
\hline \multicolumn{4}{|l|}{ Device use posture } \\
\hline Lying on sides & 78.8 & $89 / 113$ & 0.002 \\
\hline Lying on back & 74.2 & $118 / 159$ & 0.016 \\
\hline Lying on stomach & 74.0 & $74 / 100$ & 0.116 \\
\hline Standing & 73.5 & $61 / 83$ & 0.206 \\
\hline Sitting on floor & 76.0 & $57 / 75$ & 0.087 \\
\hline Sitting on couch/chair & 67.7 & $180 / 266$ & 0.813 \\
\hline \multicolumn{4}{|l|}{ Sitting posture } \\
\hline Without back support & 78.8 & $63 / 80$ & 0.016 \\
\hline Device in lap & 76.6 & $111 / 145$ & 0.002 \\
\hline Device on stand & 71.6 & $78 / 109$ & 0.316 \\
\hline Holding device with hands & 71.3 & $134 / 188$ & 0.122 \\
\hline Device flat on desk & 73.1 & $114 / 156$ & 0.053 \\
\hline Using a tablet stand & 65.5 & $131 / 200$ & 0.222 \\
\hline
\end{tabular}

back support and with the tablet in lap were significantly associated with symptoms during use.

Results of the current study showed that females were significantly more likely to have symptoms during use, especially in the neck and upper shoulder regions. This finding was consistent with the current literature on the prevalence of neck and shoulder dysfunctions. For example, according to the data from Stockholm Public Health Cohort study, the one-year prevalence of neck pain was $25 \%$ for women and $16 \%$ for men. Also, women are more likely to develop neck pain than men and less likely to recover ${ }^{23}$. In addition, the prevalence of neck and shoulder musculoskeletal symptoms in our study population of university students, faculty, staff, and alumni was much higher (up to 60\%) than in the general population. This is likely because of the sedentary behavior and the associated posture commonly seen in this group ${ }^{1,24,25)}$.

Gender differences in anthropometry and biomechanics may explain the disparity in neck and shoulder musculoskeletal symptoms. It has been shown that in the workplace, women assume neck flexion more often ${ }^{26}$. Karlqvist et al. examined computer mouse tasks and reported that female computer operators who are shorter and narrow-shouldered exhibited more extreme postures ${ }^{27}$. Furthermore, Won et al., compared gender difference in applied forces, upper extremity muscle activities, and upper extremity postures during computer tasks ${ }^{28)}$. They found that when typing, women have significantly higher normalized keyboard forces than men and tend to have higher muscle activities, and less neutral shoulder postures. The muscle activities and shoulder postures were also higher for the office workers with smaller stature. In addition, the study found that shoulder width and arm length were significantly negatively correlated with normalized typing forces, muscle activation levels, and postural measurements. While a tablet computer is not excessively heavy, users may maintain the posture for extended time (i.e. $>40 \%$ of subjects in this study use more than 3 hours per day). The female gender's generally lower muscle strength and smaller body size may predispose them to neck and shoulder symptoms during such use.

For individuals performing computer related activities, a previous study suggested that prolonged sitting and having the neck in forward flexion were risk predictors for neck pain ${ }^{29}$. Neck flexion postures can lead to an increase in gravitational load moment on the cervical spine, which increases cervical extensor muscle activity and may cause muscle strain of the neck extensors if such posture is prolonged ${ }^{30}$. Our study revealed that the odds of having symptoms during use for individuals who sit in a chair without back support, which may be related to a "slump" position, are 2.231 times greater than the odds of those 
sitting with back support. It has been shown that in a slump sitting position, greater cervical and thoracic extensor activities are required to support the head in the forward position. The combination of neck flexion and cervical extensor activities may produce specific stress regions and cause postural neck pain ${ }^{31)}$. On the other hand, sitting postures that offer support to the lumbo-pelvic region of the spine in a neutral position may significantly reduce the levels of the cervical extensor activities. In addition, a recent study concluded that positions that cause the gaze angle less than 45 degrees from neutral (downward gaze) can cause significant increases neck extensor strain ${ }^{30}$. This was consistent with our findings that placing the tablet in the lap or flat on the desk were significant risk factors for neck and shoulder symptoms during use. Perhaps supportive to this finding was our results that the students reported higher prevalence of neck and shoulder symptoms (73.4\%) during the use of tablet computer relative to other studied roles (52-64.9\%). University students in the U.S. typically do not have a permanent workstation and are constantly moving between classes. It may be more common for the students to use their tablet computers in compromised postures such as placing them in the lap while sitting without back support. More research is needed to elucidate the cause of the observed high prevalence in this subgroup.

Our results showed that using the tablet computer in more uncommon postures such as lying on the side or on the back was significantly associated with symptoms. This was in agreement with previous findings that non-neutral joint angles from non-desk usage of laptop computers can lead to greater levels of discomfort ${ }^{32}$. Additionally, sustained non-neutral joint angles during laptop use has also been reported to exacerbate symptoms of the neck and upper back ${ }^{33)}$. The side lying postures during tablet use can potentially induce non-neutral joint angles and stress in upper extremities and cervical spine. With this posture, musculoskeletal structures are at risk of abnormal and sustained forces. This posture is unique for tablet computers due to their flat profile when compared to laptop or desktop computers. Further research is needed to examine the musculoskeletal stress resulting from maintaining this posture during extended use of tablet computers.

To our knowledge, this was the first study to assess the prevalence and risk factors of neck and shoulder musculoskeletal symptoms related to the use of touchscreen tablet computers. While the results were informative, the observational nature of the study design prevented direct inference of our results. This study had a number of methodological limitations: first, we could not control for confounding factors such as the types of tablet computer used, previous injury, and exposure to other technology. Second, there may have been a gender selection bias in this study since there were more female respondents. Third, at the time of this study (2013-14), larger smart phones ( $>5$ ") were uncommon. The usage behavior observed in this study may not extrapolate to these newer devices. Lastly, our sample was limited to the students, faculty, staff, and alumni of a university in the U.S. Readers should exercise caution when generalizing findings of this study to other populations.

In summary, touchscreen tablet computers are useful tools that have penetrated our daily lives in a remarkably short time. The current study showed that there were apparent musculoskeletal health implications related to the use of such devices. Female gender, existing neck and shoulder symptoms, and sitting without back support during tablet use were shown as the most important risk factors.

\section{Conflict of interest}

None.

\section{REFERENCES}

1) Hoy DG, Protani M, De R, et al.: The epidemiology of neck pain. Best Pract Res Clin Rheumatol, 2010, 24: 783-792. [Medline] [CrossRef]

2) Kanchanomai S, Janwantanakul P, Pensri P, et al.: Risk factors for the onset and persistence of neck pain in undergraduate students: 1-year prospective cohort study. BMC Public Health, 2011, 11: 566. [Medline] [CrossRef]

3) De Loose V, Burnotte F, Cagnie B, et al.: Prevalence and risk factors of neck pain in military office workers. Mil Med, 2008, 173: 474-479. [Medline] [CrossRef]

4) Feuerstein M, Shaw WS, Nicholas RA, et al.: From confounders to suspected risk factors: psychosocial factors and work-related upper extremity disorders. J Electromyogr Kinesiol, 2004, 14: 171-178. [Medline] [CrossRef]

5) Linton SJ: A review of psychological risk factors in back and neck pain. Spine, 2000, 25: 1148-1156. [Medline] [CrossRef]

6) Fejer R, Kyvik KO, Hartvigsen J: The prevalence of neck pain in the world population: a systematic critical review of the literature. Eur Spine J, 2006, 15: 834-848. [Medline] [CrossRef]

7) Cassou B, Derriennic F, Monfort C, et al.: Chronic neck and shoulder pain, age, and working conditions: longitudinal results from a large random sample in France. Occup Environ Med, 2002, 59: 537-544. [Medline] [CrossRef]

8) McLean SM, May S, Klaber-Moffett J, et al.: Risk factors for the onset of non-specific neck pain: a systematic review. J Epidemiol Community Health, 2010, 64: 565-572. [Medline] [CrossRef]

9) Chang CH, Amick BC 3rd, Menendez CC, et al.: Daily computer usage correlated with undergraduate students' musculoskeletal symptoms. Am J Ind Med, 2007, 50: 481-488. [Medline] [CrossRef]

10) Katz JN, Amick BC, Carroll BB, et al.: Prevalence of upper extremity musculoskeletal disorders in college students. Am J Med, 2000, 109: 586-588. [Medline] [CrossRef]

11) Schlossberg EB, Morrow S, Llosa AE, et al.: Upper extremity pain and computer use among engineering graduate students. Am J Ind Med, $2004,46: 297-303$. [Medline] [CrossRef]

12) Cagnie B, Danneels L, Van Tiggelen D, et al.: Individual and work related risk factors for neck pain among office workers: a cross sectional study. Eur Spine 
J, 2007, 16: 679-686. [Medline] [CrossRef]

13) Waersted M, Hanvold TN, Veiersted KB: Computer work and musculoskeletal disorders of the neck and upper extremity: a systematic review. BMC Musculoskelet Disord, 2010, 11: 79. [Medline] [CrossRef]

14) Marcus M, Gerr F, Monteilh C, et al.: A prospective study of computer users: II. Postural risk factors for musculoskeletal symptoms and disorders. Am J Ind Med, 2002, 41: 236-249. [Medline] [CrossRef]

15) Ming Z, Zaproudina N: Computer use related upper limb musculoskeletal (ComRULM) disorders. Pathophysiology, 2003, 9: 155-160. [Medline] [CrossRef]

16) Davis KG, Hammer MJ, Kotowski SE, et al.: An ergonomic comparison of data entry work using a keyboard vs. touch screen input device while standing and sitting. J Ergonomics, 2014, S4: 007

17) Zeman E: Tablets to edge PCs in Q4. 2013, 2013.

18) Rainie L, Smith A: Tablet and E-reader ownership update. 2013, 2013: The number of Americans ages 16 and older who own tablet computers has grown to $35 \%$, and the share who have e-reading devices like Kindles and Nooks has grown to $24 \%$. Overall, the number of people who have a tablet or an e-book reader among those 16 and older now stands at $43 \%$.

19) Schools Shift from Textbooks to Tablets. 2013, 2018

20) Berolo S, Wells RP, Amick BC 3rd: Musculoskeletal symptoms among mobile hand-held device users and their relationship to device use: a preliminary study in a Canadian university population. Appl Ergon, 2011, 42: 371-378. [Medline] [CrossRef]

21) Straker LM, Coleman J, Skoss R, et al.: A comparison of posture and muscle activity during tablet computer, desktop computer and paper use by young children. Ergonomics, 2008, 51: 540-555. [Medline] [CrossRef]

22) Young JG, Trudeau M, Odell D, et al.: Touch-screen tablet user configurations and case-supported tilt affect head and neck flexion angles. Work, 2012, 41 : 81-91. [Medline]

23) Skillgate E, Magnusson C, Lundberg M, et al.: The age- and sex-specific occurrence of bothersome neck pain in the general population--results from the Stockholm public health cohort. BMC Musculoskelet Disord, 2012, 13: 185. [Medline] [CrossRef]

24) Ariëns GA, Bongers PM, Douwes M, et al.: Are neck flexion, neck rotation, and sitting at work risk factors for neck pain? Results of a prospective cohort study Occup Environ Med, 2001, 58: 200-207. [Medline] [CrossRef]

25) Szeto GP, Straker L, Raine S: A field comparison of neck and shoulder postures in symptomatic and asymptomatic office workers. Appl Ergon, 2002, 33: 75-84. [Medline] [CrossRef]

26) Wahlstedt K, Norbäck D, Wieslander G, et al.: Psychosocial and ergonomic factors, and their relation to musculoskeletal complaints in the Swedish workforce. Int J Occup Saf Ergon, 2010, 16: 311-321. [Medline] [CrossRef]

27) Karlqvist LK, Bernmark E, Ekenvall L, et al.: Computer mouse position as a determinant of posture, muscular load and perceived exertion. Scand J Work Environ Health, 1998, 24: 62-73. [Medline] [CrossRef]

28) Won EJ, Johnson PW, Punnett L, et al.: Upper extremity biomechanics in computer tasks differ by gender. J Electromyogr Kinesiol, 2009, 19: 428-436. [Medline] [CrossRef]

29) Côté P, van der Velde G, Cassidy JD, et al. Bone and Joint Decade 2000-2010 Task Force on Neck Pain and Its Associated Disorders: The burden and determinants of neck pain in workers: results of the Bone and Joint Decade 2000-2010 Task Force on Neck Pain and Its Associated Disorders. Spine, 2008, 33: S60-S74. [Medline] [CrossRef]

30) Straker L, Skoss R, Burnett A, et al.: Effect of visual display height on modelled upper and lower cervical gravitational moment, muscle capacity and relative strain. Ergonomics, 2009, 52: 204-221. [Medline] [CrossRef]

31) Caneiro JP, O'Sullivan P, Burnett A, et al.: The influence of different sitting postures on head/neck posture and muscle activity. Man Ther, 2010, 15: 54-60. [Medline] [CrossRef]

32) Gold JE, Driban JB, Yingling VR, et al.: Characterization of posture and comfort in laptop users in non-desk settings. Appl Ergon, 2012, 43: 392-399. [Medline] [CrossRef]

33) Straker L, Jones KJ, Miller J: A comparison of the postures assumed when using laptop computers and desktop computers. Appl Ergon, 1997, 28: 263-268. [Medline] [CrossRef] 